Purdue University Purdue e-Pubs

$12-1-2003$

\title{
Dynamics and Topology Optimization of Piezoelectric Fans
}

P Buermann

Arvind Raman

S V. Garimella

Purdue University, sureshg@purdue.edu

Follow this and additional works at: http://docs.lib.purdue.edu/coolingpubs

Buermann, P; Raman, Arvind; and Garimella, S V., "Dynamics and Topology Optimization of Piezoelectric Fans" (2003). CTRC Research Publications. Paper 49.

http://dx.doi.org/10.1109/TCAPT.2002.809111

This document has been made available through Purdue e-Pubs, a service of the Purdue University Libraries. Please contact epubs@purdue.edu for additional information. 


\title{
Dynamics and Topology Optimization of Piezoelectric Fans
}

\author{
Philipp Bürmann ${ }^{1}$, Arvind Raman ${ }^{2}$ and Suresh V. Garimella \\ School of Mechanical Engineering, Purdue University, \\ West Lafayette, IN 47907-1288 USA
}

Keywords: piezoelectric fans, resonators, portable electronics cooling

\begin{abstract}
Piezoelectric fans are very low power, small, very low noise, solid-state devices that have recently emerged as viable thermal management solutions for a variety of portable electronics applications including laptop computers, cellular phones and wearable computers. Piezoelectric fans utilize piezoceramic patches bonded onto thin, low frequency flexible blades to drive the fan at its resonance frequency. The resonating, low frequency blade creates a streaming airflow directed at key electronics components. The optimization of a piezoelectric fan with two symmetrically placed piezoelectric patches is investigated through an analytical Bernoulli-Euler model as well as a finite element (FE) model of the composite piezo-beam. The closed form analytical solution is used to demonstrate that different optimal piezoceramic-to-blade length ratios and piezoceramic-to-blade thickness ratios exist for maximizing the electromechanical coupling factor (EMCF), tip deflection and rotation. Such optimization procedures provide simple design guidelines for the development of very-low power, high flow rate piezoelectric fans.
\end{abstract}

\footnotetext{
${ }^{1}$ Currently at the Department of Solid Mechanics, Technical University-Dresden, Germany

${ }^{2}$ Corresponding author, raman@ecn.purdue.edu, 765-494-5733
} 


\section{INTRODUCTION}

Piezoelectric fans are solid-state resonant devices that use piezoelectric excitation to drive a thin blade into resonance to create a fluid flow for electronics cooling. Piezoelectric fans were first discussed in the early seventies (Toda [1]). However the recent surge in the functionality of portable electronics devices has generated renewed interest in the use of piezoelectric fans ([2], [3]) as a very compact, low power, noiseless air cooling technology for applications as varied as cellular phones, laptop computers and automobile multimedia boxes. Some sample configurations of piezoelectric fans demonstrating a piezoceramic bonded to a thin shimstock are shown in Figure 1.

The major part of this work discusses the dynamic and electromechanical optimization of these fans. However, some basic experimental results describing the fluidic and thermal performance of these fans are described first, to highlight both the significant potential as well as the challenges of the integration of piezoelectric fans in portable electronics applications. Figure 2 shows the transient and highly complex flow field caused by a piezoelectric fan starting from rest. The fan is made of stainless steel shimstock and is $6 \mathrm{~cm}$ long (See Figure 1 for the configuration). The flow is visualized using water droplets illuminated with a sheet of light. The flow generated by the fan is clearly seen to have primary components in a direction transverse to the fan blade, with vortices being shed off the fan tip. The fluid is drawn from the clamped section (at the left in the photographs in Figure 2) along the length of the fan, and then ejected in transverse directions. At the right end of the domain shown is an impingement plate, held at a distance of $2 \mathrm{~cm}$ from the tip of the fan. Its presence influences the flow significantly, as shown by the streamlines sketched onto 
the photograph in Figure 3. The ejection of flow from the left along the fan blade is deflected away from the blade by the recirculating flow pattern near the tip of the fan. Fluid is drawn from the impingement plate towards the fan along the plane of the fan blade as part of this recirculation cell.

The complexity of the flow field generated makes it clear that the location of the fan in a given enclosure, as well as its location with respect to a heated component, are crucial determinants of the heat transfer rates achieved. In preliminary experiments, enhancements in heat transfer of over $100 \%$ compared to natural convection alone were obtained; in particular, $2 \mathrm{~W}$ of heat could be removed from a simulated chip in the presence of a piezoelectric fan, compared to only $1 \mathrm{~W}$ being dissipated under natural convection conditions. This enhancement in heat transfer was obtained at the expense of approximately $1 \mathrm{~mW}$ of power input to operate the piezofan. In these experiments, different locations of the fan with respect to the heat source resulted in different levels of heat removal. While these experimental investigations strongly support the possibility of the use of piezoelectric fans in portable electronics, much work remains in the electromechanical, and fluid-structure interaction optimization of piezoelectric resonant fans.

Piezoelectric resonators are used as actuators (Pan et al. [4], Rivory et al. [5], Tiersten [6], Seeley and Chattopadhyay [7], Seshu \& Naganathan [8]) and sensors (Lee and Saravanos [9], Aldraihem and Kheir [10], Main et al. [11]) for a wide variety of applications including piezoelectric fans, optical beam choppers, ultrasonic motors, microelectromechanical density sensors, and resonating viscometers. For these applications, little seems to be known about an optimal actuator-beam configuration including patch location, actuator patch-to-beam length ratio, and patch-to-beam thickness ratio. Moreover, the optimization 
criterion is application-dependent and can vary between maximal electromechanical coupling factor (EMCF), optimal mode shapes and frequencies, and tip deflections. In light of this, we focus in this work on analytical solutions of the dynamic response optimization of a piezoelectric fan modeled as a partially electroded (on both faces) elastic beam near resonance.

Several authors (Pan et al. [4], Wang and Wang [12], Khdeir and Aldraihem [13], Brennan et al. [14], Lee and Saravanos [9], Crawley and Anderson [15], Aldraihem and Kheir [10], Seeley and Chattopadhyay [7], Seshu and Naganathan [8], Yang [16]) have investigated the modeling and optimization for static deflection/actuation of piezoelectricelastic composite structures.

Analytical, experimental and computational investigations of the dynamic response of such structures are presented in Rivory et al. [5], Tiersten [6], Barboni et al. [17], Main et al. [11], Lobontiu et al. [18], Shen [19], Pan and Hansen [20], Abramovich [21], Crawley and de Luis [22], and Strambi et al. [23]. Rivory et al. [24] and Tiersten [6] present an analytical dynamical model. However, the free vibration problem is not considered and thus the electromechanical coupling factor is not computed. In Barboni et al. [17] a similar approach to a solution for the forced mode shape is derived after the time-dependent terms have been eliminated. In Main et al. [11] dynamic response of a beam that is fully covered by the patch is considered. Lobontiu et al. [18] present a beam that is partially covered by two piezoelectric patches. However, the additional mass and stiffness of the piezoelectric patches are not considered, while the actuation is included as two external point bending moments applied on the beam. The coupling effects between curvature and electric field are neglected. The forcing from the piezoelectric patches in Shen [19] is modeled as an in- 
ternal bending moment distribution in the beam. The resulting equations are written in state equation form and the control issues are discussed. However, no coupling between piezoelectric patches and beam is taken into account. A lumped parameter approach is followed in Pan and Hansen [20]. Mass, damping, stiffness and forcing are lumped as parameters in a one degree-of-freedom model. The forcing term is included explicitly and an extensive parametric study is carried out. This work is not based on a continuum model. The wave response in beams and plates with attached piezoelectric patches is considered in Abramovich [21]. However, the excitation is included through Dirac delta and Heaviside step functions implying the neglect of coupling between piezoelectric patch and the substrate. In Crawley and de Luis [22] an infinitely long beam attached to piezoelectric patches is considered and is treated as a wave generator. The forcing is included as external point bending moments neglecting the coupling between the piezoelectric patch and substrate. Strambi et al. [23] present a static and dynamic model of a beam with two piezoelectric patch actuators, incorporating true coupling between the piezoelectric patch and beam. However, optimization issues are not discussed and their approach requires a priori knowledge of the phase difference between forcing and response. Wolf [24] presents a comprehensive analysis of optimal electromechanical coupling factors in the context of a piezoelectric patch attached to an infinitely long beam. A similar approach is followed in the present work however a focus is placed on the analysis for a finite length beam. This leads to substantially different analysis techniques and optimization issues.

Finite element approaches for the optimization of piezoelectric structures are presented in Benjeddou et al. [25], Chandrashekhara and Varadarajan [26], Silva and Kikuchi [27], Yang [16], and Zhai et al. [28]. In Chandrashekhara and Varadarajan [27] a cantilever 
beam with segmented shear piezoelectric actuators is analyzed using sandwich beam finite elements. In Yang [16] the determination of the optimal thickness of a single piezoelectric actuator is addressed. In Zhai et al. [28] a topology optimization of a geometrically complex, stack actuator is performed. Finite element based optimization techniques are very expensive computationally. The focus of the present paper is to develop a closed-form analytical solution for a resonating, composite piezo-beam and utilize this solution to develop guidelines for optimal fan configurations. Finite element models of the fan are used to confirm the validity of the analytical solution.

\section{ELECTROMECHANICAL MODELING AND ANALYSIS}

Consider the beam shown in Figure 4. The beam is of total length $\mathrm{L}_{3}$, while the piezoelectric patches are bonded perfectly to the beam and are of length $\mathrm{L}_{2}-\mathrm{L}_{1}$. The thickness of the beam and the actuators is given as $2 h$ and $h_{p}$, respectively, where the coordinate $\mathrm{x}_{3}$ is measured from the neutral axis of the beam. The widths of the beam and patches are $2 \mathrm{~b}$. The part of the fan from the clamp up to the beginning of the beam will be referred to as region 1, the section covered by the actuators as region 2 and the section from the end of the patches to the tip of the beam as region 3.

\subsection{Analytical Model}

The transverse displacements of the neutral axis of the substrate in each region $v_{i}\left(x_{1}, t\right)$, $\mathrm{i}=1,2,3$, are measured with respect to the longitudinal coordinate $\mathrm{x}_{1}$ along the neutral axis of the substrate. The composite piezoelectric fan is modeled as a composite Bernoulli- 
Euler beam. The equations of motion governing the transverse deflection of the piezoelectric fan can be derived through the use of linear piezoelectric constitutive relations, the simplifying Bernoulli-Euler assumptions and application of Hamilton's principle inclusive of strain energy and electromechanical energy terms in the formulation. The resulting equations of motion for the three regions and the corresponding boundary conditions can be shown to be [24]

$$
\begin{aligned}
& \mathrm{EI}_{1}^{\prime \prime \prime \prime}+\mathrm{m}_{\mathrm{s}} \ddot{\mathrm{v}}_{1}=0, \quad \mathrm{Kv}_{2}^{\prime \prime \prime \prime}+\mathrm{m}_{\mathrm{p}} \ddot{\mathrm{v}}_{2}=0, \quad \mathrm{EIv}_{3}^{\prime \prime \prime \prime}+\mathrm{m}_{\mathrm{s}} \ddot{\mathrm{v}}_{3}=0 \\
& \mathrm{v}_{1}(0, \mathrm{t})=0, \quad \mathrm{v}_{1}^{\prime}(0, \mathrm{t})=0, \quad \mathrm{v}_{1}\left(\mathrm{~L}_{1}, \mathrm{t}\right)=\mathrm{v}_{2}\left(\mathrm{~L}_{1}, \mathrm{t}\right), \quad \mathrm{v}_{1}^{\prime}\left(\mathrm{L}_{1}, \mathrm{t}\right)=\mathrm{v}_{2}^{\prime}\left(\mathrm{L}_{1}, \mathrm{t}\right), \\
& \mathrm{EI}_{1}^{\prime \prime}\left(\mathrm{L}_{1}, \mathrm{t}\right)=\mathrm{Kv}_{2}^{\prime \prime}\left(\mathrm{L}_{1}, \mathrm{t}\right)+\mathrm{a}_{4}(\mathrm{t}) \mathrm{A}_{\mathrm{p}}, \quad \mathrm{EI} \mathrm{v}_{1}^{\prime \prime \prime}\left(\mathrm{L}_{1}, \mathrm{t}\right)=\mathrm{Kv}_{2}^{\prime \prime \prime}\left(\mathrm{L}_{1}, \mathrm{t}\right), \\
& \mathrm{v}_{2}\left(\mathrm{~L}_{2}, \mathrm{t}\right)=\mathrm{v}_{3}\left(\mathrm{~L}_{2}, \mathrm{t}\right), \mathrm{v}_{2}^{\prime}\left(\mathrm{L}_{2}, \mathrm{t}\right)=\mathrm{v}_{3}^{\prime}\left(\mathrm{L}_{2}, \mathrm{t}\right), \mathrm{Kv}_{2}^{\prime \prime}\left(\mathrm{L}_{2}, \mathrm{t}\right)+\mathrm{a}_{4}(\mathrm{t}) \mathrm{A}_{\mathrm{p}}=\mathrm{EI}_{3}^{\prime \prime}\left(\mathrm{L}_{3}, \mathrm{t}\right), \\
& \mathrm{Kv}_{2}^{\prime \prime \prime}\left(\mathrm{L}_{2}, \mathrm{t}\right)=\mathrm{EI}_{3}^{\prime \prime \prime}\left(\mathrm{L}_{2}, \mathrm{t}\right), \mathrm{v}_{3}^{\prime \prime}\left(\mathrm{L}_{3}, \mathrm{t}\right)=0, \mathrm{v}_{3}^{\prime \prime}\left(\mathrm{L}_{3}, \mathrm{t}\right)=0
\end{aligned}
$$

where the primes are derivatives with respect to $\mathrm{x}_{1}$

$$
\mathrm{m}_{\mathrm{s}}=\rho_{\mathrm{s}} \mathrm{A}_{\mathrm{s}}, \mathrm{EI}=\mathrm{E}_{\mathrm{s}} \mathrm{I}_{\mathrm{s}}, \mathrm{m}_{\mathrm{p}}=\rho_{\mathrm{s}} \mathrm{A}_{\mathrm{s}}+2 \rho_{\mathrm{p}} \mathrm{A}_{\mathrm{p}}, \mathrm{K}=\mathrm{E}_{\mathrm{s}} \mathrm{A}_{\mathrm{s}}+4 \mathrm{a}_{2} \mathrm{I}_{\mathrm{p}}+4 \mathrm{a}_{3} \mathrm{~A}_{\mathrm{p}}
$$

and $\rho_{s}, \rho_{\mathrm{p}}, \mathrm{E}_{\mathrm{s}}, \mathrm{A}_{\mathrm{s}}, \mathrm{A}_{\mathrm{p}}, \mathrm{I}_{\mathrm{s}}, \mathrm{I}_{\mathrm{p}}$ denote respectively the mass density of the beam and the piezoelectric patch, the Young's modulus of the substrate, the areas of cross section of the substrate and patch, and the area moment of inertias of the substrate and patch. The coefficients $\mathrm{a}_{2}, \mathrm{a}_{3}, \mathrm{a}_{4}$ are related to the piezoelectric-structure coupling and are given by

$$
\mathrm{a}_{2}=\frac{1}{2}\left(\mathrm{E}_{\mathrm{p}}+\frac{\mathrm{e}_{31}^{2}}{\varepsilon_{33}}, \mathrm{a}_{3}=\frac{-\mathrm{e}_{31}^{2}\left(2 \mathrm{~h}+\mathrm{h}_{\mathrm{p}}\right)^{2}}{8 \varepsilon_{33}}, \mathrm{a}_{4}(\mathrm{t})=-\frac{\mathrm{e}_{31}\left(2 \mathrm{~h}+\mathrm{h}_{\mathrm{p}}\right) \Delta \Phi(\mathrm{t})}{2 \mathrm{~h}_{\mathrm{p}}}\right.
$$

where $\mathrm{E}_{\mathrm{p}}, \mathrm{e}_{31}, \varepsilon_{33}$ are respectively the Young's modulus of the piezoelectric patch, the product of $E_{p}$ and the piezoelectric material coefficient $d_{31}$, and the product of the relative di- 
electric constant $\mathrm{K}_{33}$ and the free space permitivity $\varepsilon_{0} . \Delta \Phi(\mathrm{t})$ is the potential difference between the top and bottom of the electrodes of the piezoelectric patches.

It must be noted here that no explicit forcing term appears in equation (1). The piezoelectric excitation is only contained in the boundary conditions because $\mathrm{a}_{4}(\mathrm{t})$ depends on the potential difference $\Delta \Phi(\mathrm{t})$ (equation 3). In addition to the boundary conditions at the clamp and the free end of the beam, there are matching conditions at each interface between two regions. The deflection and slope, and the internal bending moment and the internal shear force are related to each other. Note that there is a time-dependent jump in bending moment and that the stiffness term $\mathrm{K}$ consists of the stiffness of the underlying substrate $\mathrm{E}_{\mathrm{s}} \mathrm{I}_{\mathrm{s}}$, the added mechanical stiffness of the piezoelectric actuators $4 \mathrm{a}_{2} \mathrm{I}_{\mathrm{p}}$ and an electromechanical coupling term $4 a_{3} A_{p}$. For free vibrations of the piezoelectric fan, $\Delta \Phi(\mathrm{t})$ can either be 0 (short-circuited or SC electrodes) or be generated naturally by the bending vibrations (open circuited or OC electrodes). For forced vibrations, $\Delta \Phi(\mathrm{t})$ is a prescribed, harmonic waveform with a frequency matching the short-circuited fan frequency.

The free vibration eigenvalue problem is solved piecewise in each region by use of expressions for the prescribed potential difference $\Delta \Phi(\mathrm{t})$ and through separation of variables in equation (1):

$$
\mathrm{v}_{\mathrm{i}}\left(\mathrm{x}_{1}, \mathrm{t}\right)=\varphi_{\mathrm{i}}\left(\mathrm{x}_{1}\right) \mathrm{e}^{\mathrm{i} \omega t}, \quad \varphi_{\mathrm{i}}(\mathrm{x})=\mathrm{A}_{\mathrm{i}} \cos \left(\beta_{\mathrm{i}} \mathrm{x}_{1}\right)+\mathrm{B}_{\mathrm{i}} \sin \left(\beta_{\mathrm{i}} \mathrm{x}_{1}\right)+\mathrm{C}_{\mathrm{i}} \cosh \left(\beta_{\mathrm{i}} \mathrm{x}_{1}\right)+\mathrm{D}_{\mathrm{i}} \sinh \left(\beta_{\mathrm{i}} \mathrm{x}_{1}\right)
$$

$\mathrm{i}=1,2,3$ and the wavenumbers $\beta_{\mathrm{i}}$ are given by

$$
\beta_{1}=\beta_{3}=\left(\frac{m_{s}}{E_{s} I_{s}} \omega^{2}\right)^{\frac{1}{4}}, \beta_{2}=\left(\frac{m_{p}}{K} \omega^{2}\right)^{\frac{1}{4}}
$$


It can be shown that the partial differential equations and boundary conditions (1) are satisfied exactly with the above solution forms. Substitution of (5) into the boundary conditions (1), casting the system in matrix form and setting its determinant to zero, the eigenvalues $\omega$ of the fan can be computed. For both the SC and OC cases, all unknown coefficients $A_{i}, B_{i}, C_{i}, D_{i}$ are expressed in terms of any one amongst them. This last coefficient is found by normalizing the mode shapes in the standard way with respect to the mass operator Meirovitch [29]. This yields an exact closed form analytical solution for the normalized free vibration mode.

When the beam is driven by the piezoelectric actuators the matching conditions (1) for internal bending moments become non-homogeneous and non-autonomous. To homogenize the boundary conditions, the following transformations are introduced:

$$
v_{1}\left(x_{1}, t\right)=w_{1}\left(x_{1}, t\right), \quad v_{2}\left(x_{1}, t\right)=w_{2}\left(x_{1}, t\right)+h\left(x_{1}\right) a_{4}(t) A_{p}, \quad v_{3}\left(x_{1}, t\right)=w_{3}\left(x_{1}, t\right)
$$

The function $\mathrm{h}\left(\mathrm{x}_{1}\right)$ is determined such that the boundary conditions (1) are satisfied and rendered homogeneous. The resulting equations for $\mathrm{w}_{\mathrm{i}}\left(\mathrm{x}_{1}, \mathrm{t}\right)$ feature homogeneous partial differential equations with explicit forcing terms and can be solved using Galerkin's method:

$$
\mathrm{w}_{\mathrm{i}}\left(\mathrm{x}_{1}, \mathrm{t}\right)=\varphi_{\mathrm{i}}\left(\mathrm{x}_{1}\right) \mathrm{q}(\mathrm{t}), \mathrm{i}=1,2,3
$$

where $\varphi_{\mathrm{i}}\left(\mathrm{x}_{1}\right)$ are the eigenfunctions for the SC free vibration problem. Substitution of the previously computed $\varphi_{\mathrm{i}}\left(\mathrm{x}_{1}\right)$ into (7) and subsequently into the homogenized equations for $\mathrm{w}_{\mathrm{i}}\left(\mathrm{x}_{1}, \mathrm{t}\right)$, and taking inner products in succession with the $\varphi_{\mathrm{i}}\left(\mathrm{x}_{1}\right)$, leads to the following discretized equations near resonance: 


$$
\begin{aligned}
& \ddot{\mathrm{q}}+2 \varsigma \omega_{\mathrm{SC}} \dot{\mathrm{q}}+\mathrm{I}_{5} \mathrm{q}=-\mathrm{I}_{2} \mathrm{~A}_{\mathrm{p}} \ddot{\mathrm{a}}_{4}-\mathrm{I}_{6} \mathrm{~A}_{\mathrm{p}} \mathrm{a}_{4} \\
& \mathrm{I}_{2}=\mathrm{m}_{\mathrm{p}} \int_{\mathrm{L}_{1}}^{\mathrm{L}_{2}} \varphi_{2}\left(\mathrm{x}_{1}\right) \mathrm{h}\left(\mathrm{x}_{1}\right) \mathrm{d} \mathrm{x}_{1}, \mathrm{I}_{6}=\mathrm{K} \int_{\mathrm{L}_{1}}^{\mathrm{L}_{2}} \varphi_{2}\left(\mathrm{x}_{1}\right) \mathrm{h}^{\prime \prime \prime}\left(\mathrm{x}_{1}\right) \mathrm{d} \mathrm{x}_{1}, \\
& \mathrm{I}_{5}=\mathrm{EI} \int_{0}^{\mathrm{L}_{1}} \varphi_{1}\left(\mathrm{x}_{1}\right) \varphi_{1}{ }^{\prime \prime \prime \prime}\left(\mathrm{x}_{1}\right) \mathrm{d} \mathrm{x}_{1}+\mathrm{K} \int_{\mathrm{L}_{1}}^{\mathrm{L}_{2}} \varphi_{2}\left(\mathrm{x}_{1}\right) \varphi_{2}{ }^{\prime \prime \prime \prime}\left(\mathrm{x}_{1}\right) \mathrm{d} \mathrm{x}_{1}+\mathrm{EI} \int_{\mathrm{L}_{2}}^{\mathrm{L}_{31}} \varphi_{3}\left(\mathrm{x}_{1}\right) \varphi_{3}{ }^{\prime \prime \prime}\left(\mathrm{x}_{1}\right) \mathrm{dx} \mathrm{x}_{1}=\omega_{\mathrm{SC}}^{2}
\end{aligned}
$$

Note that linear viscous damping has been added through the damping ratio $\varsigma$. Emergence

of the short-circuited natural frequency $\omega_{S C}$ in equation (8) is a consequence of the use of SC eigenfunctions in Galerkin's method. The particular steady state solution of (8) is

$$
\begin{gathered}
\mathrm{q}_{\mathrm{p}}(\mathrm{t})=\mathrm{F}(\Omega) \sin (\Omega \mathrm{t}-\gamma(\Omega)) \\
\mathrm{F}(\Omega)=\sqrt{\frac{\left(\mathrm{I}_{6}-\mathrm{I}_{2}\right) \hat{\mathrm{V}}^{2}}{\left(\Omega^{2}-\omega_{\mathrm{SC}}^{2}\right)^{2}+4 \Omega^{2} \zeta^{2}}}, \gamma(\Omega)=-\arctan \left[\frac{\omega_{\mathrm{SC}}^{2}-\Omega^{2}}{2 \zeta \omega_{\mathrm{SC}} \Omega}\right], \hat{\mathrm{V}}=-2 \mathrm{e}_{31}\left(2 \mathrm{~h}+\mathrm{h}_{\mathrm{p}}\right) \mathrm{b} \overline{\mathrm{V}}
\end{gathered}
$$

and $\overline{\mathrm{V}}$ is the amplitude of excitation in volts. $\gamma(\Omega)$ is the phase difference between fan vibration and voltage input.

\subsection{Finite Element Model}

To confirm the validity of the analytical model the piezo-beam is modeled in ANSYS 5.7 using 3-D linear solid brick elements. The piezoelectric constitutive equations are utilized in their three-dimensional planar isotropic form and the properties chosen for the computation are listed in Table 1. Some three-dimensional piezoelectric constants are not retrievable from the manufacturer's data and are approximated from typical handbook values. A regular three-dimensional mesh was generated using 3D brick piezoelectric 20-node elements. Overall 16,008 nodes were used in the computation. Piezoelectric and elastic beam properties were assigned to the respective volumes. All nodes above and below the 
piezoelectric patches were assigned a voltage coupling corresponding to the SC/OC electrical boundary conditions.

\subsection{Comparison of Analytical and FE Model}

For typical actuator lengths and one value of thickness $\left(h_{p}=0.178 \mathrm{~mm}\right)$ the $\mathrm{SC}$ and OC natural frequencies of the analytical and FE model corresponding to the first and second bending modes were compared and found to be in excellent agreement (Table 2). For a fixed length of patch $\mathrm{L}_{2}-\mathrm{L}_{1}=6.5 \mathrm{~mm}$ the mass-normalized first and second SC and OC mode shapes are compared in Figure 5. The results show excellent agreement, with the difference between the analytical and FE predictions increasing with increasing mode number.

\section{OPTIMIZATION RESULTS AND DISCUSSION}

Now three parameters of the system are allowed to vary: (i) the length of the patch, while $L_{1}$ is held fixed at $0.5 \mathrm{~mm}$, (ii) location of patch $\mathrm{L}_{1}$ while the length of the patch is kept fixed at $6.5 \mathrm{~mm}$ and (iii) the height of the patch. All other geometric constants are held constant (Table 1). $\mathrm{L}_{2}$ is varied from $3 \mathrm{~mm}$ to $27 \mathrm{~mm}$ in steps of $1 \mathrm{~mm}$ while $\mathrm{h}_{\mathrm{p}}$ ranges from $0.127 \mathrm{~mm}$ to $0.254 \mathrm{~mm}$ in increments of $0.0254 \mathrm{~mm}$. Only the first bending mode was considered, it being the most common resonant mode used in piezoelectric fans. First the natural frequencies for $\mathrm{SC}$ and $\mathrm{OC}$ electrodes are calculated. These are used to compute the dynamic electromechanical coupling factors (EMCF), while for the forced response only the SC electrode mode shapes and natural frequencies are sufficient. The dynamic EMCF is a measure of the quantity of electrical energy that can be converted into 
mechanical energy in the resonator and is defined as

$$
\mathrm{EMCF}=\sqrt{\frac{\omega_{\mathrm{OC}}^{2}-\omega_{\mathrm{SC}}^{2}}{\omega_{\mathrm{OC}}^{2}}}
$$

The variation of EMCF's as a function of the patch-to-beam thickness ratio and patchto-beam length ratio (for fixed $\mathrm{L}_{1}$ ) is plotted in Figure 6 a together with a contour plot of the resulting surface. The figure clearly reveals an optimum patch-beam thickness ratio as well as patch-beam length ratio for maximizing the EMCF. Specifically thickness ratio around 0.8 and length ratio around 0.6 would maximize the EMCF for this choice of material combination, and for a fixed $\mathrm{L}_{1}$, clamp-patch distance. Moreover the drop off from optimal performance is the least severe if the design errs towards greater patch length or thickness from optimal. This variation is closely connected to the variation with optimization parameters of the fan natural frequencies. Piezoelectric patches add distributed elastic and piezoelectric stiffness as well as mass to the fan. For small patch lengths, the added stiffness effect dominates and increases the natural frequencies while at longer patch lengths the added mass effect reduces the natural frequencies. Therefore the natural frequencies and consequently EMCF are maximal at an optimal value of patch-to-beam length ratio. However, the clamp-patch distance $\mathrm{L}_{1}$ affects significantly, both the optimal thickness ratio and the length ratio for maximal EMCF. This is demonstrated in Figure $6 \mathrm{~b}$ where for a fixed patch length $\mathrm{L}_{2}-\mathrm{L}_{1}=6.5 \mathrm{~mm}$ the clamp-patch distance $\mathrm{L} 1$ is varied from $0.1\left(\mathrm{~L}_{2}-\mathrm{L}_{1}\right)$ to $\mathrm{L}_{3}-\left(\mathrm{L}_{2}-\mathrm{L}_{1}\right)$ in equal increments of $1 \mathrm{~mm}$. It is clearly seen that for the chosen material properties and patch length, the patch should be placed as close as possible to the clamp. The corresponding optimal patch thickness ratio now reduces to 0.35 . 
While the dynamic EMCF's are well-defined rational measures of the electromechanical energy conversion of a resonator, the optimization of fan performance with respect to objectives that are related closer to fluidic actuation are also attempted. The optimization objective is to maximize some measure of the actual system response governed by equation (8). It is important to note that in the absence of a systematic physical damping model, the modal damping factor $\zeta$ is assumed to be independent of the natural frequency. Thus the lower the natural frequency of the first mode, the lower is its modal damping $2 \varsigma \omega_{S C}$. This observation plays a key role in explaining the following results.

1. Using the $S C$ mode shapes and the relation $v_{3}\left(L_{3}, t\right)=w_{3}\left(L_{3}, t\right)=\varphi_{3}\left(L_{3}\right) q(t)$, the maximum tip deflection can be given as $\bar{v}_{3}\left(L_{3}\right)=\phi_{3}\left(L_{3}\right) F\left(\omega_{0}\right)$ where $\omega_{0}$ is the damped natural frequency of the fan with short-circuited electrodes. The variation of the maximum tip deflection as a function of the patch-to-beam thickness ratio and patch-to-beam length ratio is plotted in Figure 6c. From the corresponding contour plot it can be seen that for patch thickness ratio greater than one, there exists an optimal length ratio. For example at thickness ratio 1.3 , a length ratio of 0.5 maximizes the resonant amplitude. However if both the patch thickness and length ratio are allowed to vary freely, the optimal design indicates that the patch should be as thin as possible and should cover as much of the substrate as possible. This resulting optimal design is quite different from the design based on maximal EMCF. The results in Figure 6c can be explained as follows. The resonant amplitude at resonance is inversely proportional to the modal damping. The modal damping being assumed proportional to the short-circuited natural frequency, an optimal design at- 
tempts to reduce the SC natural frequency to maximize resonant amplitude. This occurs when the patch covers most of the beam and if its thickness nearly vanishes. This leads to physically unacceptable optimal designs. Further Figure 6d presents the resonant amplitude variation as the patch location is varied from near clamp to near the free end as in Figure 6b. The accompanying contour plot indicates that the patch is optimally located when it is as close as possible to the clamp. This result clearly indicates that the use of forced response to optimize piezo fans requires accurate a priori knowledge of the damping mechanisms of the piezo fan, in particular the dependence on frequency of the modal damping factors

2. Maximizing the tip rotation of the fan is expected to lead to an increase in the centrifugal forces on the fluid under actuation. For this reason, the variation of the tip rotation defined as $\bar{v}_{3}{ }^{\prime}\left(\mathrm{L}_{3}\right)=\varphi_{3}{ }^{\prime}\left(\mathrm{L}_{3}\right) \mathrm{F}\left(\omega_{0}\right)$ was also plotted as a function of the patch-to-beam thickness ratio, patch location and patch-to-beam length ratio. However the resulting contour plots and optimal locations are very similar to that achieved using the maximum resonant amplitude criterion. For this reason the results are not shown for this case. However, the performance drop for off-optimal configurations is sharper if the optimization criterion is posed in terms of tip rotation as compared to tip deflection. Tip rotation may also be of interest when considering high tip velocities where vortex shedding can significantly affect the performance of the piezoelectric fan.

The optimal designs based on measures of the forced vibration response require an accurate prescription of the fan damping model and are expected to be difficult to implement 
for achieving physically acceptable fan designs. However, optimal designs based on measures of the free vibration characteristics (EMCF's for example) lead to physically acceptable optimal designs. The most direct approach for fan optimization is to couple the fluid dynamics with fan motion. This is the area of current research by the authors.

\section{CONCLUSIONS}

A closed-form analytical solution of the dynamic response of a resonant, composite piezoelectric beam is developed for the optimization of piezoelectric fans. The predicted open- and short-circuited frequencies and mode shapes were in excellent agreement with the results of finite element computations. The results indicate that the optimal values of patch-to-beam ratio, patch location and patch-to-beam thickness are different depending on whether the optimization criterion is posed in terms of (i) maximal electromechanical coupling factor (EMCF), and (ii) maximal tip deflection and rotation at resonance. However use of optimization criteria based on measures of the forced vibration response require accurate damping models to realize physically acceptable optimal designs. Such analytical and FE models are expected to provide simple design guidelines for the development of low power, high flow rate piezoelectric fans. Coupled with their other desirable features of low noise, small size, and low power, piezoelectric fans offer an exciting new approach for thermal management in a variety of portable electronics applications.

\section{Acknowledgements}

The authors would like to thank Mr. Tolga Acikalin and Mr. Sudipta Basak for their help with the manuscript. The authors also acknowledge the financial support from the Purdue Office of Technology Commercialization and their industrial sponsors in the Purdue NSF 
Cooling Technologies Research Center (http://widget.ecn.purdue.edu/ CTRC). 


\section{REFERENCES}

[1] M. Toda, Theory of air flow generation by a resonant type PVF2 bimorph cantilever vibrator, Ferroelectrics 22(3-4): 911-918, 1979.

[2] J. H., Yoo, J.I. Hong, W. Cao, Piezoelectric ceramic bimorph coupled to thin metal plate as cooling fan for electronic devices, Sensors and Actuators A, 79 (1): 8-12, 2000.

[3] J. S. Campbell et al., IEEE Intersociety Conference on Thermal Phenomena, 43-50, 1998.

[4] J. Pan, C.H. Hansen, and S. D. Snyder, A study of the response of a simply supported beam to excitation by a piezoelectric actuator, Journal of Intelligent Material Systems and Structures 3: 3-16, 1992.

[5] J. F. Rivory, C. H. Hansen, and J. Pan, Further studies of the dynamic response of a simply supported beam excited by a pair of out-of-phase piezoelectric actuators, Journal of Intelligent Material Systems and Structures 5: 654-663, 1994.

[6] H. F. Tiersten, Linear piezoelectric plate vibrations. New York: Plenum Press, 1969.

[7] C.E. Seeley and A. Chattopadhyay, The development of an optimization procedure for the design of intelligent structures, Smart Materials and Structures 2: 135-146, 1993.

[8] P. Seshu and N. G. Naganathan, Finite-element analysis of strain transfer in an induced strain actuator, Smart Materials and Structures 7: 76-88, 1998.

[9] H.J. Lee, and D. A. Saravanos, Coupled layerwise analysis of thermopiezoelectric composite beams, AIAA 34 (6): 1231-1237, 1996.

[10] O. J., Aldraihem and A. A. Kheir, Smart beams with extension and thickness-shear piezoelectric actuators, Smart Materials and Structures 9: 1-9, 2000. 
[11] J. A. Main, E. Garcia, and D. Howard, Optimal placement and sizing of paired piezoactuators in beams and plates, Smart Materials and Structures 3: 373-381, 1994.

[12] Q. Wang and C. M. Wang, Optimal placement and size of piezoelectric patches on beams from the controllability perspective, Smart Materials and Structures 9: 558-567, 2000.

[13] A. A. Khdeir, and O. J. Aldraihem, Deflection analysis of beams with extension and shear piezoelectric patches using discontinuity functions, Smart Materials and Structures 10: 212-220, 2001.

[14] M. J. Brennan, S. J. Elliot, and R. J. Pinnington, The dynamic coupling between piezoceramic actuators and a beam, Journal of the Acoustical Society of America 102 (4): 1931-1942, 1997.

[15] E. F. Crawley, and E. H. Anderson, Detailed model of piezoceramic actuation of beams, Journal of Intelligent Material Systems and Structures 1: 5-25, 1990.

[16] J. S. Yang, Equations for the flexural motion of elastic plates with partially electroded piezoelectric actuators, Smart Materials and Structures 6: 485-490, 1997.

[17] R. Barboni, A. Mannini, E. Fantini, and P. Gaudenzi, Optimal placement of PZT actuators for the control of beam dynamics, Smart Materials and Structures 9: 110-120, 2000.

[18] N. Lobontiu, M. Goldfarb, E. Garcia, Achieving maximum tip deflection during resonant excitation of piezoelectrically actuated beams, Journal of Intelligent Material Systems and Structures 10: 900-913, 1999. 
[19] M-H. H. Shen, A new modeling technique for piezoelectrically excited beams, Computers \& Structures 57 (3): 361-366, 1995.

[20] X. Pan, X. and C. H. Hansen, Piezoelectric crystal vs point force excitation of beams and plates, Journal of Intelligent Material Systems and Structures 5: 363-370, 1994.

[21] H. Abramovich, Deflection control of laminated composite beams with piezoceramic layers - closed form solutions, Composite Structures 43: 217-231, 1998.

[22] E. F. Crawley and J. de Luis, Use of piezoelectric actuators as elements of intelligent structures, AIAA 25 (10): 1373-1385, 1987.

[23] G. Strambi, R. Barboni, and P. Gaudenzi, Pin-force and Euler-Bernoulli models for analysis of intelligent structures, AIAA 33 (9): 1746-1749, 1995.

[24] K. D. Wolf, Electromechanical energy conversion in asymmetric piezoelectric bending actuators. Ph.D. Thesis, Technical University-Darmstadt, Germany, 2000.

[25] A. Benjeddou, M. A. Trinidade, and R. Ohayon, New shear actuated smart structure beam finite element, AIAA 37 (3): 378-383, 1999.

[26] K. Chandrashekhara, and S. Varadarajan, Adaptive shape control of composite beams with piezoelectric actuators, Journal of Intelligent Material Systems and Structures 8: 112124, 1997.

[27] E. C. N. Silva, and N. Kikuchi, Design of piezoelectric transducers using topology optimization, Smart Materials and Structures 8: 350-364, 1999.

[28] B. Zhai, S.P. Lim, K.H. Lee, C.H. Chew, S. Dong, S. and P. Lu, A design of an ultrasonic linear motor based on theoretical analysis, Smart Materials and Structures 9: 774$779,2000$. 
[29] L. Meirovitch, Principles and Techniques of Vibration, Prentice-Hall, 1997. 
Table 1: Material Properties of a Piezoelectric Fan.

\begin{tabular}{|c|c|c|}
\hline & Physical Quantity & Value \\
\hline $\mathrm{E}_{\mathrm{s}}$ & Young's Modulus of the Beam & $10 * 10^{10} \frac{\mathrm{N}}{\mathrm{m}^{2}}$ \\
\hline $\mathrm{E}_{\mathrm{p}}$ & Young's Modulus of the Actuator & $6.2 * 10^{10} \frac{\mathrm{N}}{\mathrm{m}^{2}}$ \\
\hline$\rho_{\mathrm{s}}$ & Density of the Beam & $8400 \frac{\mathrm{kg}}{\mathrm{m}^{3}}$ \\
\hline$\rho_{\mathrm{p}}$ & Density of the Piezoelectric Actuator & $7800 \frac{\mathrm{kg}}{\mathrm{m}^{3}}$ \\
\hline $2 \mathrm{~h}$ & Height of the Beam & $0.1016 \mathrm{~mm}$ \\
\hline $\mathrm{h}_{\mathrm{p}}$ & Height of the Piezoelectric Actuator & $0.127 \mathrm{~mm}-0.254 \mathrm{~mm}$ (varied) \\
\hline $2 b$ & Width of Beam and Piezoelectric Actuator & $8.89 \mathrm{~mm}$ \\
\hline $\mathrm{L}_{1}$ & Length of Region 1 & $0.5 \mathrm{~mm}$ \\
\hline $\mathrm{L}_{2}$ & Length of Region 1 and 2 & $3 m m-27 m m($ varied $)$ \\
\hline $\mathrm{L}_{3}$ & Overall Length of the Structure & $27.424 \mathrm{~mm}$ \\
\hline $\mathrm{K}_{33}$ & Relative Dielectric Constant & 3800 \\
\hline$\varepsilon_{0}$ & Permitivity of Free Space & $8.9 * 10^{-12} \frac{\mathrm{C}}{\mathrm{Vm}}$ \\
\hline $\mathrm{d}_{31}$ & Piezoelectric Strain Coefficient & $-320 * 10^{-12} \frac{\mathrm{m}}{\mathrm{v}}$ \\
\hline$\zeta$ & Damping Ratio & 0.04 \\
\hline
\end{tabular}


Table 2: A comparison of the natural frequencies predicted by the analytical and the FE model. The FE model is used as a reference when computing the error.

\begin{tabular}{|c|c|c|c|}
\hline Mode & L2=7mm & L2=14mm & L3=21 mm \\
\hline 1st sc anal & $121.47 \mathrm{~Hz}$ & $190.23 \mathrm{~Hz}$ & $163.69 \mathrm{~Hz}$ \\
1st sc FEM & $122.85 \mathrm{~Hz}$ & $188.40 \mathrm{~Hz}$ & $160.37 \mathrm{~Hz}$ \\
\%Error & $-1.12 \%$ & $0.97 \%$ & $2.07 \%$ \\
\hline 1st oc anal & $121.59 \mathrm{~Hz}$ & $190.94 \mathrm{~Hz}$ & $164.31 \mathrm{~Hz}$ \\
1st oc FEM & $123.41 \mathrm{~Hz}$ & $190.91 \mathrm{~Hz}$ & $162.55 \mathrm{~Hz}$ \\
\% Error & $-1.47 \%$ & $\sim 0 \%$ & $1.08 \%$ \\
\hline 2nd sc anal & $599.95 \mathrm{~Hz}$ & $494.08 \mathrm{~Hz}$ & $1255.42 \mathrm{~Hz}$ \\
2nd sc FEM & $603.45 \mathrm{~Hz}$ & $502.08 \mathrm{~Hz}$ & $1165.8 \mathrm{~Hz}$ \\
\% Error & $-0.579 \%$ & $-1.59 \%$ & $7.68 \%$ \\
\hline 2nd oc anal & $600.49 \mathrm{~Hz}$ & $494.08 \mathrm{~Hz}$ & $1269.26 \mathrm{~Hz}$ \\
2nd oc FEM & $607.62 \mathrm{~Hz}$ & $502.08 \mathrm{~Hz}$ & $1203.6 \mathrm{~Hz}$ \\
\% Error & $-1.17 \%$ & $-1.59 \%$ & $5.45 \%$ \\
\hline
\end{tabular}



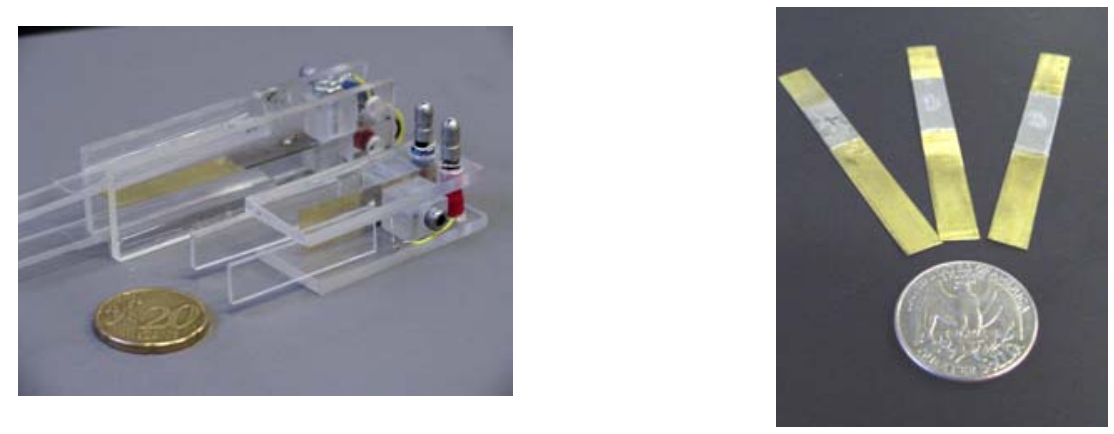

Figure 1: Sample configurations for piezoelectric fans. Piezoelectric elements attached to small flexible shimstock are driven with an $\mathrm{AC}$ voltage near resonance causing the blade to oscillate like a traditional Japanese fan. 


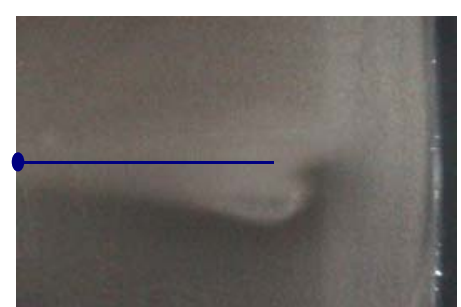

$33 \mathrm{~ms}$

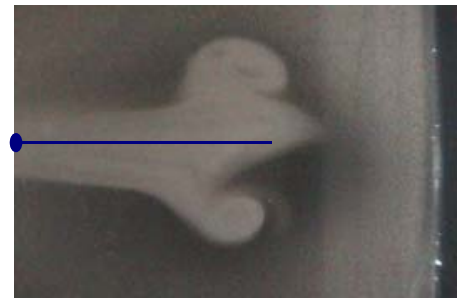

$165 \mathrm{~ms}$

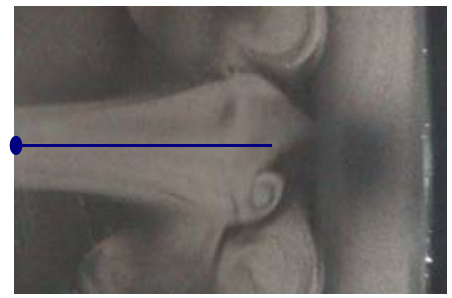

$430 \mathrm{~ms}$

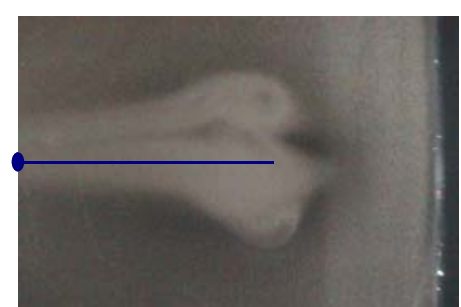

$66 \mathrm{~ms}$

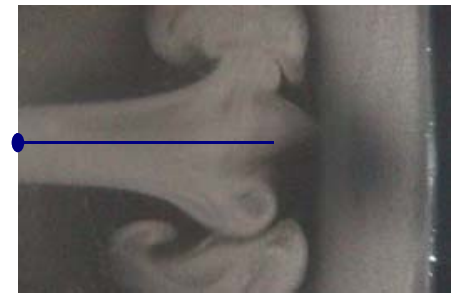

$265 \mathrm{~ms}$

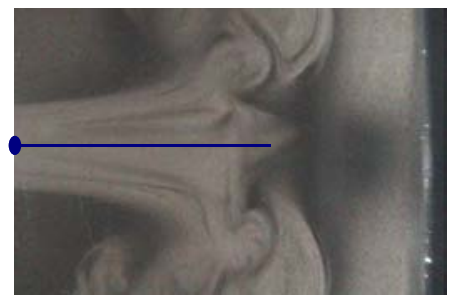

$500 \mathrm{~ms}$

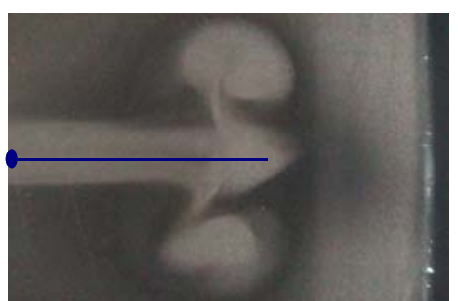

$100 \mathrm{~ms}$

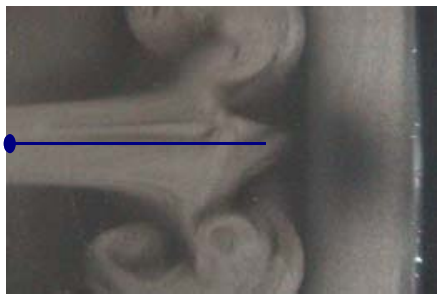

$333 \mathrm{~ms}$

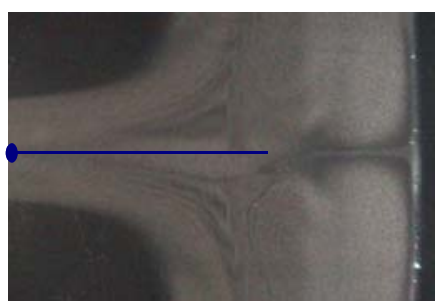

$5 \mathrm{~s}$

Figure 2: Photographs of the flow produced by a $6 \mathrm{~cm}$-long piezoelectric fan. Water droplets were used to seed the flow. The fan was driven at a resonant frequency of $23 \mathrm{~Hz}$. At the right end of the picture is a solid wall. 


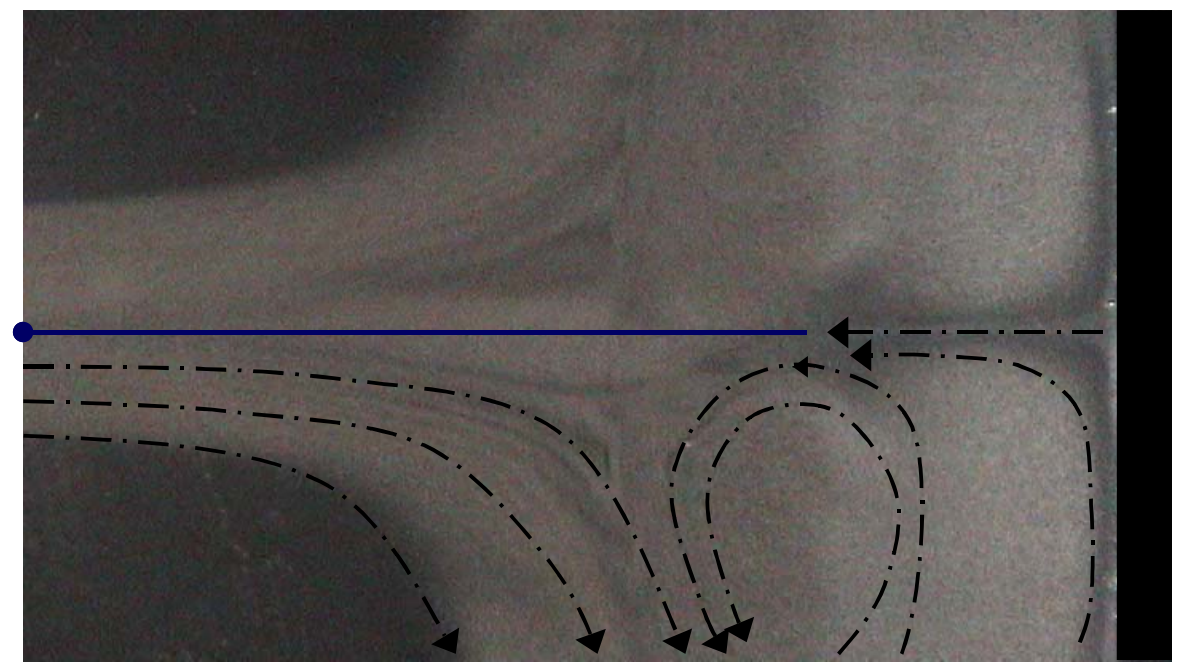

Figure 3: Sketch of the streamlines in the impingement flow field around the piezoelectric fan considered in Figure 1. 


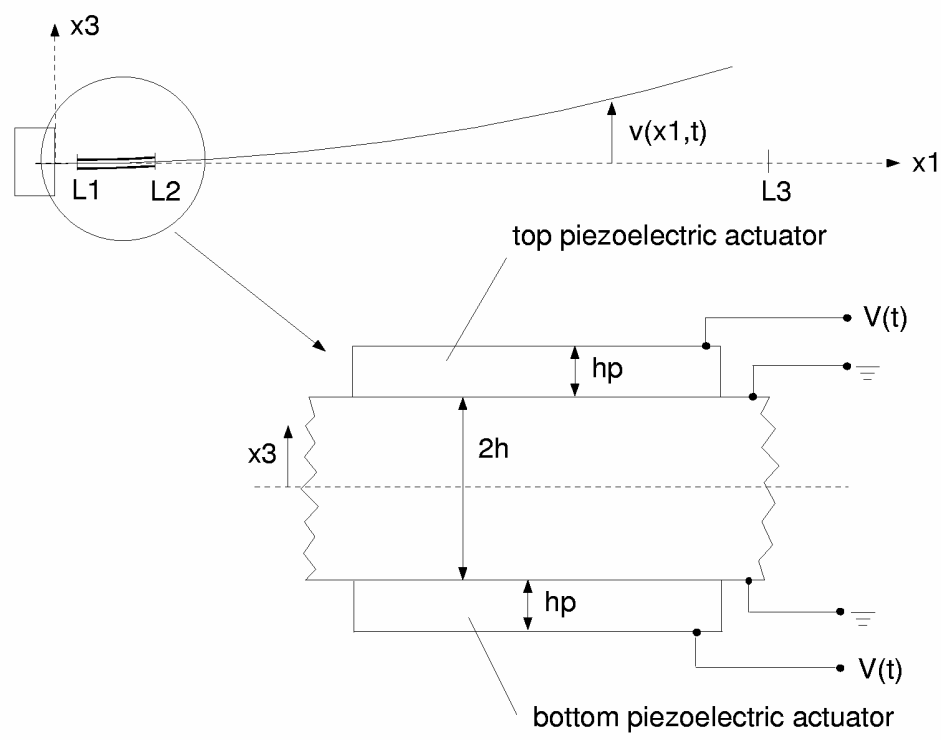

Figure 4: Piezoelectric fan geometry. The fan is driven at resonance by piezoelectric patches that are operated out-of-phase from an electronic circuit. 

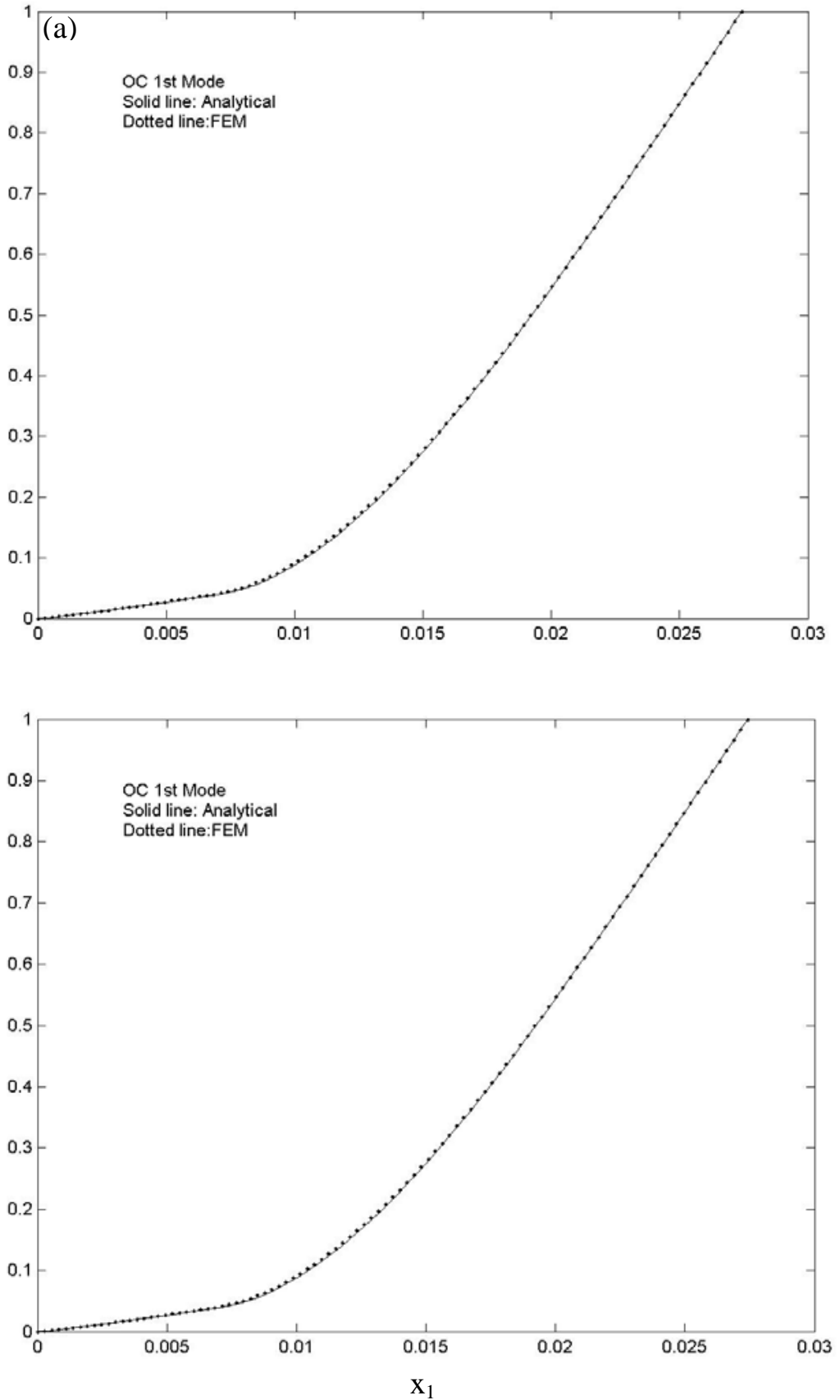

Figure 5: (a) Normalized mode shapes for the 1st bending mode, short-circuited (above), and opencircuited (below). Solid-line: analytical model, dotted line: FEM model. 

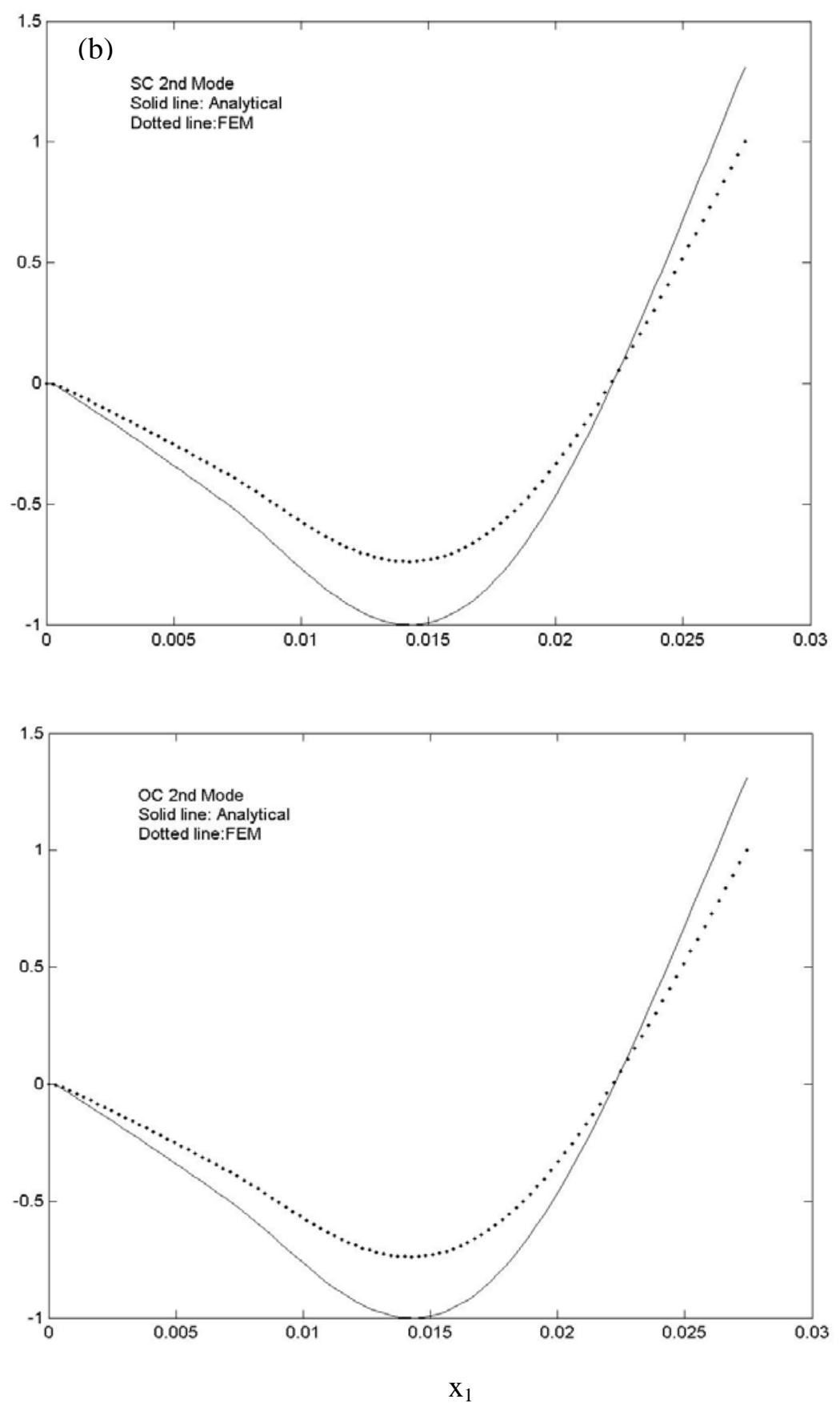

Figure 5: (b) Normalized mode shapes for the 2nd bending mode, short-circuited (above), and open-circuited (below). Solid-line: analytical model, dotted line: FEM model. 

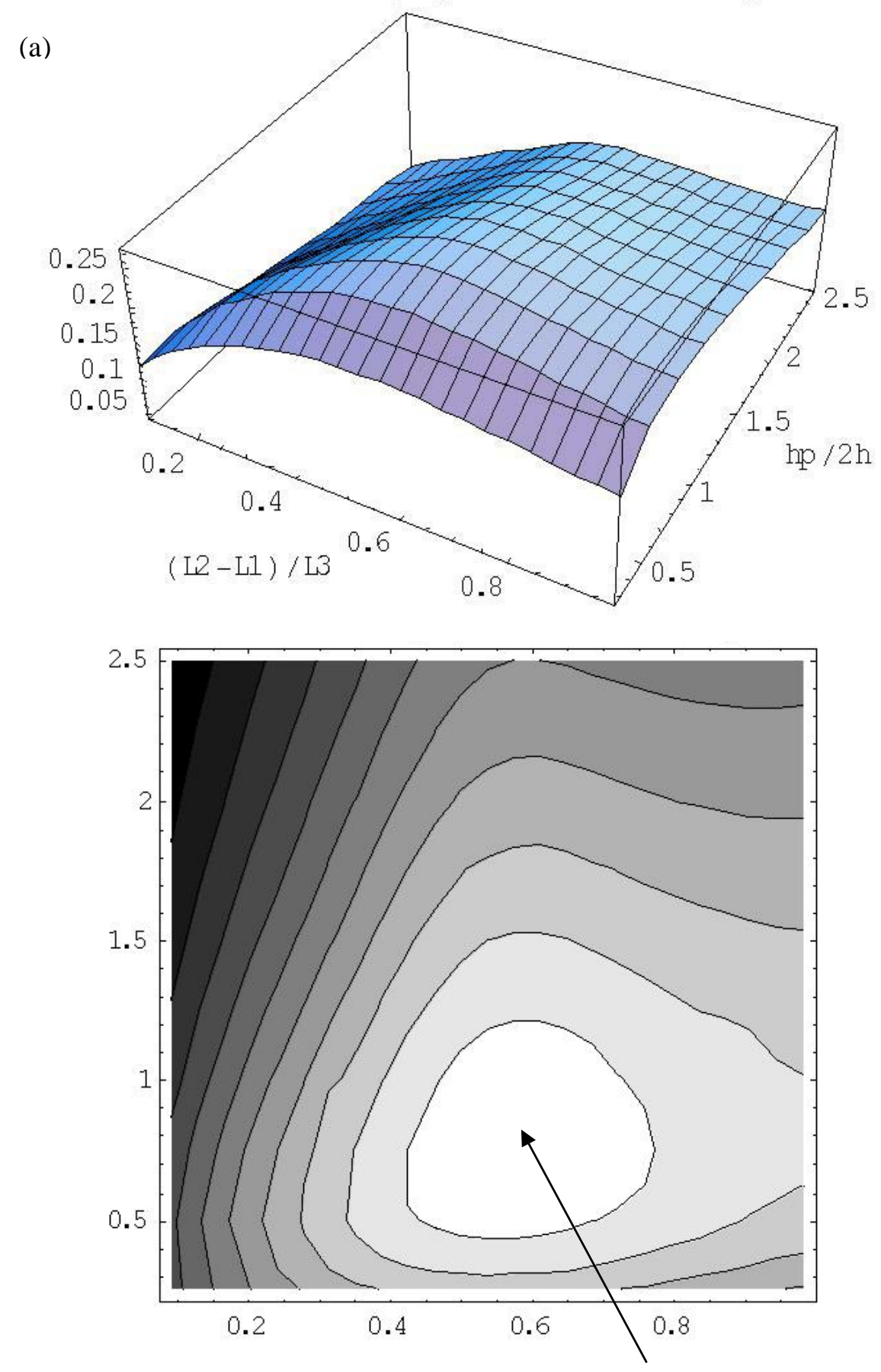

Figure 6: (a) Variation with patch-to-beam length and thickness ratio of electromechanical coupling factor (EMCF). 3D surface (above) and contour plot (below). Arrow indicates the optimum configuration. 

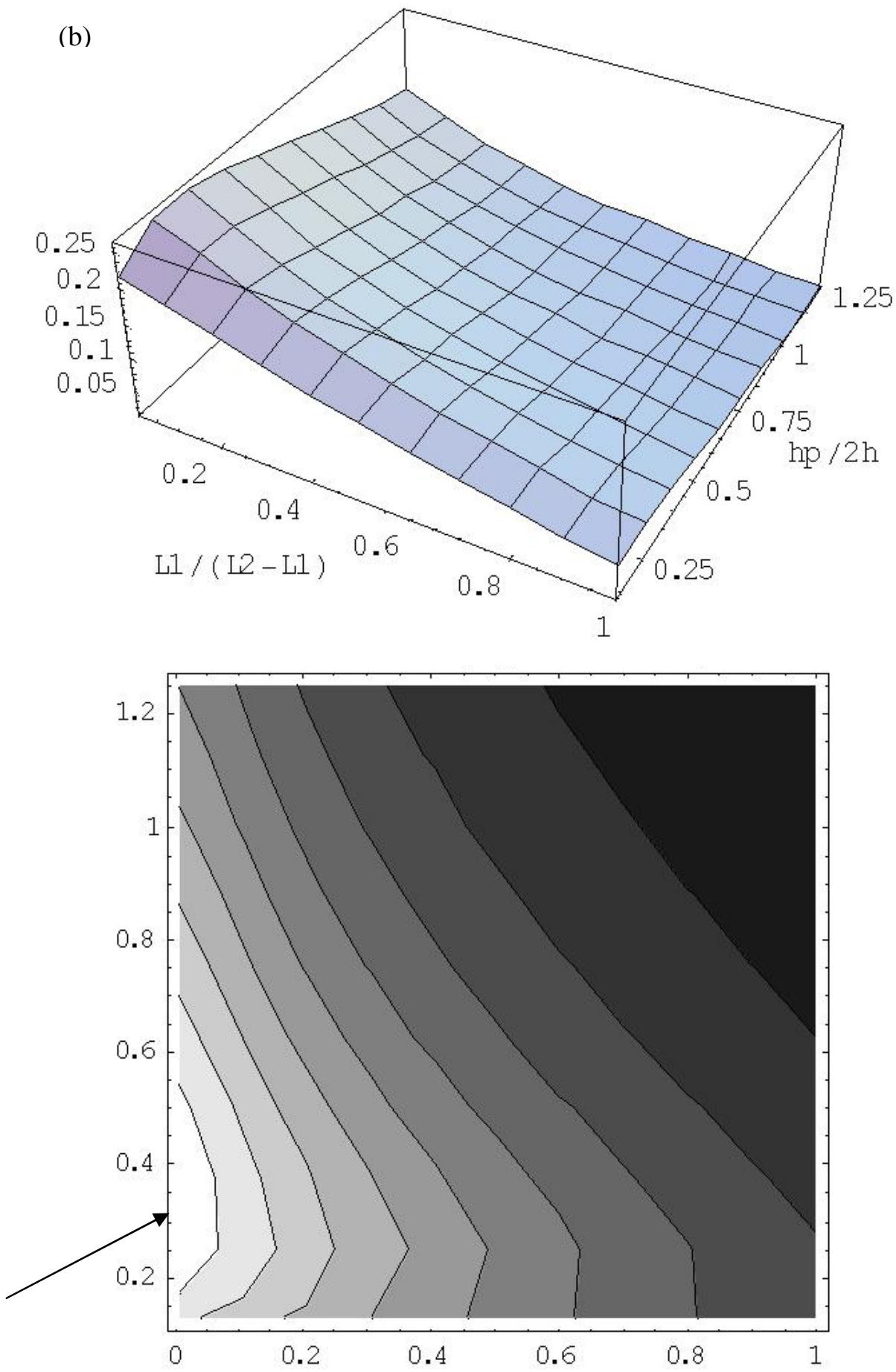

Figure 6: (b) Variation with patch location and thickness ratio of electromechanical coupling factor (EMCF). 3D surface (above) and contour plot (below). Arrow indicates the optimum configuration. 

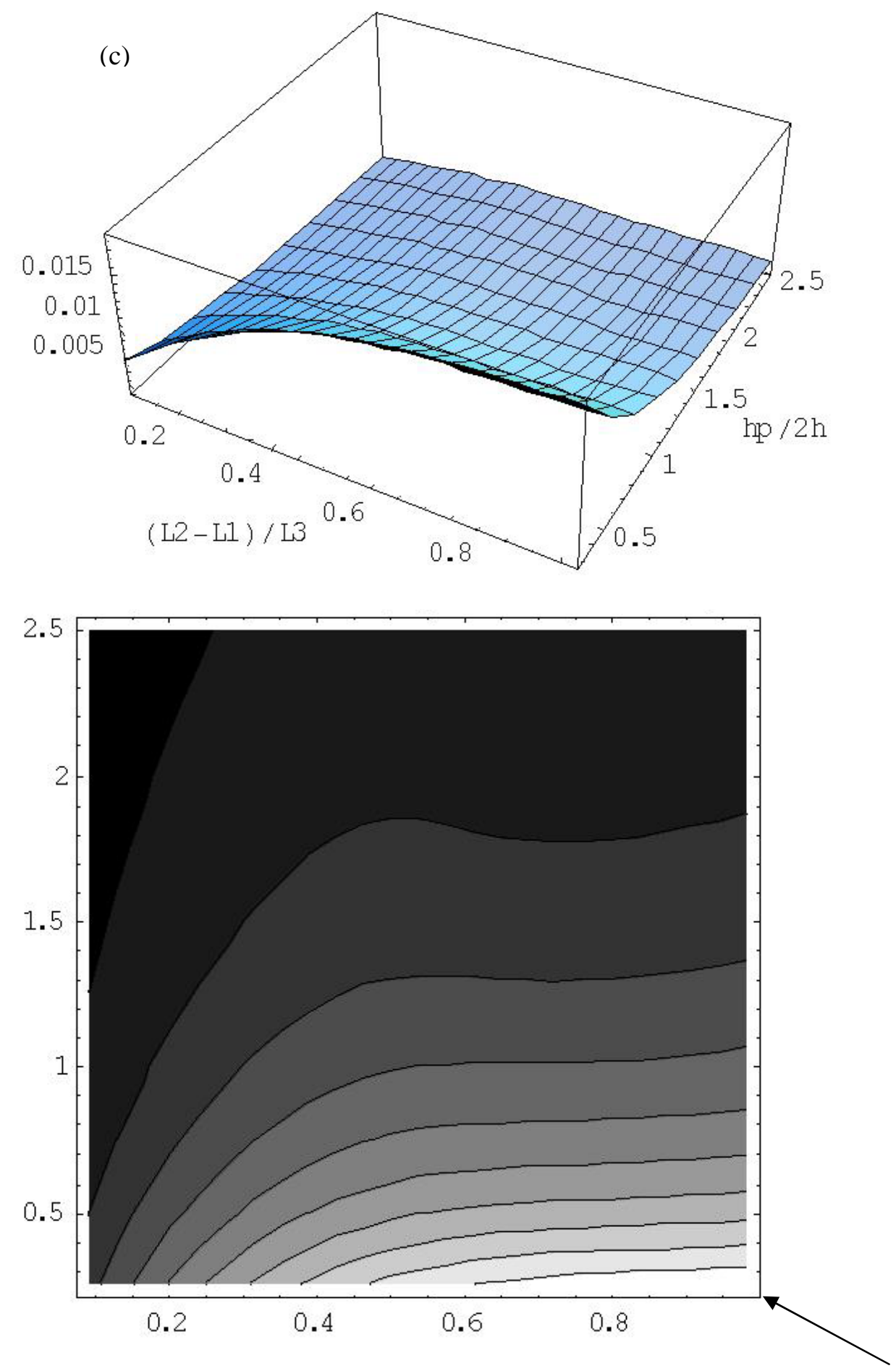

Figure 6: (c) Variation with patch-to-beam length and thickness ratio of maximum tip deflection at resonance. 3D surface (above) and contour plot (below). Arrow indicates the optimum configuration. 

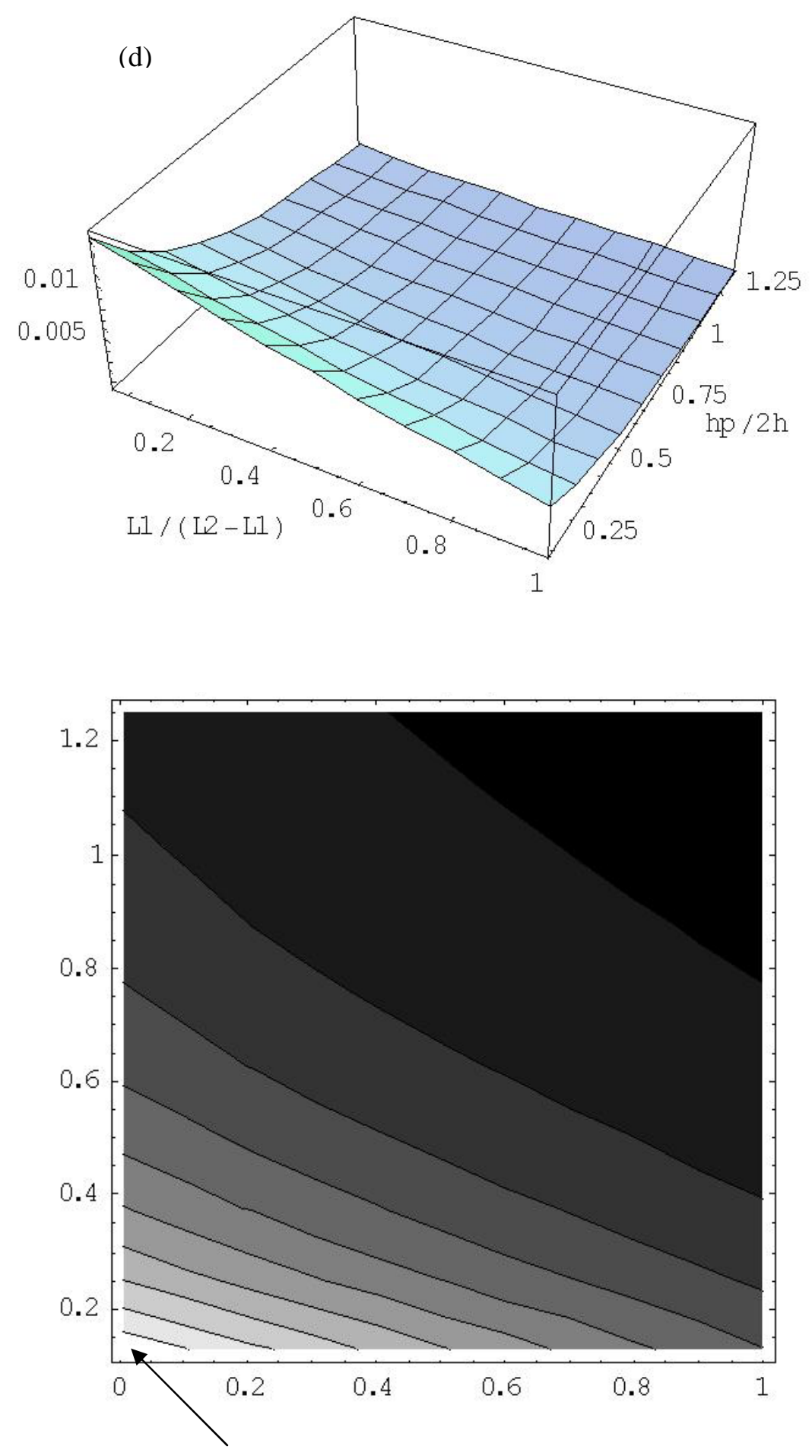

Figure 6: (d) Variation with patch location and thickness ratio of maximum tip deflection at resonance. 3D surface (above) and contour plot (below). Arrow indicates the optimum configuration. 